\title{
Using camera trap data to assess the impact of bushmeat hunting on forest mammals in Tanzania
}

\author{
Carla Hegerl, Neil D. Burgess, Martin R. Nielsen, Emanuel Martin \\ Marco Ciolli and Francesco Rovero
}

\begin{abstract}
Bushmeat hunting is a pantropical threat to rainforest mammals. Understanding its effects on species richness, community composition and population abundance is of critical conservation relevance. As data on the pre-hunting state of mammal populations in Africa are not generally available, we evaluated the impacts of illegal bushmeat hunting on the mammal community of two ecologically similar forests in the Udzungwa Mountains of Tanzania. The forests differ only in their protection status: one is a National Park and the other a Forest Reserve. We deployed systematic camera trap surveys in these forests, amounting to 850 and 917 camera days in the Forest Reserve and the National Park, respectively, and investigated differences between the two areas in estimated species-specific occupancies, detectabilities and species richness. We show that the mammal community in the Forest Reserve is degraded in all aspects relative to the National Park. Species richness was almost $40 \%$ lower in the Forest Reserve (median 18 vs 29 species, highest posterior density intervals $15-30$ and 23-47, respectively). Occupancy of most species was also reduced significantly and the functional community appeared significantly altered, with an increase in rodents, and loss of large carnivores and omnivores. Overall, our results show how ineffective reserve management, with almost absent law enforcement, leads to uncontrolled illegal hunting, which in turn has a significant impact on the mammal fauna of globally important sites for conservation.
\end{abstract}

Keywords Biodiversity conservation, bushmeat, Eastern Arc, poaching, rainforest, Tanzania, Udzungwa

Carla Hegerl (Corresponding author) Department of Animal Ecology, Evolutionary Biology Centre, Uppsala University, Norbyvägen 18D, SE-752 36 Uppsala, Sweden. E-mail carlahegerl@gmail.com

Neil D. Burgess UNEP-WCMC, Cambridge, UK, and CMEC, The Natural History Museum, University of Copenhagen, Denmark

Martin R. Nielsen Department of Food and Resource Economics, University of Copenhagen, Frederiksberg, Denmark

EMANUEL MARTiN ${ }^{*}$ Department of Wildlife Management, Sokoine University of Agriculture, Morogoro, Tanzania

MARCo Crolli Department of Civil, Environmental and Mechanical Engineering, University of Trento, Trento, Italy

Francesco Rovero* Tropical Biodiversity Section, MUSE-Museo delle Scienze, Trento, Italy

${ }^{*}$ Also at: Udzungwa Ecological Monitoring Centre, Udzungwa Mountains National Park, Tanzania

Received 1 February 2015. Revision requested 3 March 2015

Accepted 30 June 2015. First published online 9 October 2015.
To view supplementary material for this article, please visit http://dx.doi.org/10.1017/So030605315000836

\section{Introduction}

The hunting of wild animals for household consumption or trade is considered one of the biggest threats to the mammal fauna of tropical rainforests ( $\mathrm{Fa}$ et al., 2002; Milner-Gulland \& Bennett, 2003) and is particularly serious in Africa (Nielsen, 2006; Fa \& Brown, 2009; Effiom et al., 2013; Taylor et al., 2015). Rainforests are often defaunated by bushmeat hunting, as harvest rates often exceed reproduction rates where demand for bushmeat is high (Robinson \& Bennett, 2004; Rist et al., 2009). Large mammals with slow growth and reproduction rates are usually the first to become locally extinct (Brashares et al., 2001; Poulsen et al., 2011). Medium-sized terrestrial mammals are hunted using non-specific techniques, which can cause shifts in the faunal species composition (Jerozolimski \& Peres, 2003). Non-preferred mammals are also affected through bycatch and competitive or predator release (Redford, 1992; Peres \& Dolman, 2000; Linder \& Oates, 2011), with repercussions for functional plant-animal relations (Wright, 2003) and ecosystem stability (Redford, 1992; Galetti \& Dirzo, 2013).

Understanding the effects of hunting on mammal communities is of critical conservation relevance (Cullen et al., 2000; Nielsen, 2006; Bennett et al., 2007) and may be addressed indirectly by comparing forests with similar ecological characteristics and contrasting hunting pressure, because a temporal analysis within one area is often unfeasible because of a lack of data on the pre-hunting state. A robust comparison, however, needs to be based on sufficient ecological similarity of the studied sites and on unbiased estimators of the occurrence or abundance of target species and communities that account for imperfect detection (Yoccoz et al., 2001; Williams et al., 2002). For terrestrial mammals, camera trapping coupled with occupancy analysis meet such requirements (e.g. Ahumada et al., 2011; Rovero et al., 2014a) and are amenable to standardization (Silveira et al., 2003, Tobler et al., 2008; O’Brien, 2011; Rovero et al., 2013).

We conducted our study in the Udzungwa Mountains of Tanzania within the Eastern Arc, a region of outstanding value for biological endemism and biodiversity conservation 
(Burgess et al., 2007; Rovero \& De Luca, 2007; Rovero et al., $2009,2014 \mathrm{~b}$ ). The human population on the eastern lowland margins of the forest has been increasing in recent decades as the fertile land facilitates commercial production of sugar cane and rice (National Bureau of Statistics, 2013). Bushmeat hunting is illegal in all reserves within the Udzungwa range but is still widespread in reserves with ineffective management regimes (Nielsen, 2006; Topp-Jørgensen et al., 2009). The aim of this study was to understand whether and how intensive hunting altered the mammal community of a Forest Reserve with low management effectiveness, in comparison to a well-protected forest area within a National Park where hunting does not occur but which has comparable elevation range, forest type and rainfall patterns. We used camera trapping to collect data on the presence of mammals. The occupancy analytical framework we adopted corrects occupancy, or probability of presence, for potential bias as a result of varying species- and site-specific detectabilities (MacKenzie et al., 2002, 2005). This facilitates a sound comparison of hunted communities, unlike previous studies on the effects of bushmeat hunting in this area, which were based on raw indices of abundance (Topp-Jørgensen et al., 2009; Rovero et al., 2012). Specifically, we aimed to compare the mammal communities of the two forests from three perspectives: (1) species richness, (2) species-specific occupancy and detectability, and (3) functional composition.

\section{Study area}

Uzungwa Scarp Forest Reserve and Mwanihana Forest are the two largest continuous forest areas within the Udzungwa Mountains and are critical for the conservation of most of the mammalian diversity in Udzungwa forests (Shangali et al., 1998; Rovero \& De Luca, 2007; DeFries et al., 2010; Rovero et al., 2012). Mwanihana Forest covers an area of $177 \mathrm{~km}^{2}$ within the north-eastern part of Udzungwa Mountains National Park (1,990 km²; Fig. 1), which was established in 1992. Uzungwa Scarp Forest Reserve covers $200 \mathrm{~km}^{2}$ and lies c. $150 \mathrm{~km}$ south-west of the National Park; it was gazetted in 1929 and is currently a proposed Nature Reserve. Both forests are located on the eastern slopes of steep escarpments of the Udzungwa Mountains and have similar ecological characteristics (Table 1): both sites are covered by continuous forests, from lowland deciduous to submontane and montane evergreen forests, on an elevational gradient of c. 300 to $>2000 \mathrm{~m}$. They receive similar amounts of rainfall (2,000-2,500 $\mathrm{mm}$ per year), have similar temperature ranges throughout the year and grow on ancient mountains with a common geological history (Lovett, 1993; Rovero et al., 2012).

The forests differ, however, in their conservation effectiveness (Table 1): as a part of Udzungwa Mountains
National Park, Mwanihana Forest is managed by Tanzania National Parks, the well-resourced National Parks agency, and therefore hunting is rare here (Museo Tridentino di Scienze Naturali, 2007; Rovero et al., 2014a). Uzungwa Scarp Forest Reserve is managed by the Tanzania Forest Service, with few resources and lower effectiveness. A 2011 survey on the conservation state of protected areas within the Eastern Arc highlighted that illegal bushmeat hunting is the main threat to biodiversity in the Reserve, whereas it has little or no impact in the National Park (Eastern Arc Mountains Conservation Endowment Fund, 2013). The survey also suggested that indicators of conservation effectiveness are an appropriate way to approximate hunting pressure, as evidence suggests that poor law enforcement is the main reason for increased hunting activity (Nyundo et al., 2006; Topp-Jørgensen et al., 2009; Rovero et al., 2012).

Many large-bodied mammals $\left(>_{4} \mathrm{~kg}\right)$, including elephant Loxodonta africana, buffalo Syncerus caffer and leopard Panthera pardus, were locally extinct in the Reserve by the early 1970 as a result of intensive hunting for bushmeat trade (Rovero et al., 2012). As a consequence, hunters shifted their practices towards subsistence hunting, and snares and pitfall traps are now the most commonly used tools. Hunters increase the probability of catching preferred species by adapting the size of the snares and placing them on the trails used by target species. Although there is some variation in hunters' preferences, evidence from snare counts along line transects and interviews with hunters suggest that forest-dwelling, small- to medium-sized ungulates (Abbott's duiker Cephalophus spadix, Harvey's duiker Cephalophus harveyi, blue duiker Cephalophus monticola and suni Neotragus moschatus) are the preferred species (Topp-Jørgensen et al., 2009; Rovero et al., 2010, 2012). Other species, such as giant pouched rat Cricetomys gambianus, are also caught occasionally, and predominantly arboreal primates are driven by dogs into isolated trees and then shot (Rovero et al., 2012).

\section{Methods}

\section{Data collection}

In Uzungwa Scarp Forest Reserve two grids of 15 digital camera traps (UOVision IR+, UOVision Technology, Shenzhen, China) were set sequentially at a density of 1 camera per $\mathrm{km}^{2}$. The first grid was located in the northern, remote part of the Reserve (Fig. 1), at 1,653-1,848 m, and was active during 15 December 2013-14 January 2014. The second grid was located in the southern part of the Reserve and was active during 20 January-25 February 2014, at 372-1,564 m (Supplementary Fig. S1). Each camera was set on a tree to record a trail c. $2 \mathrm{~m}$ away. The area within the sensor field of the camera was cleared of ground vegetation 


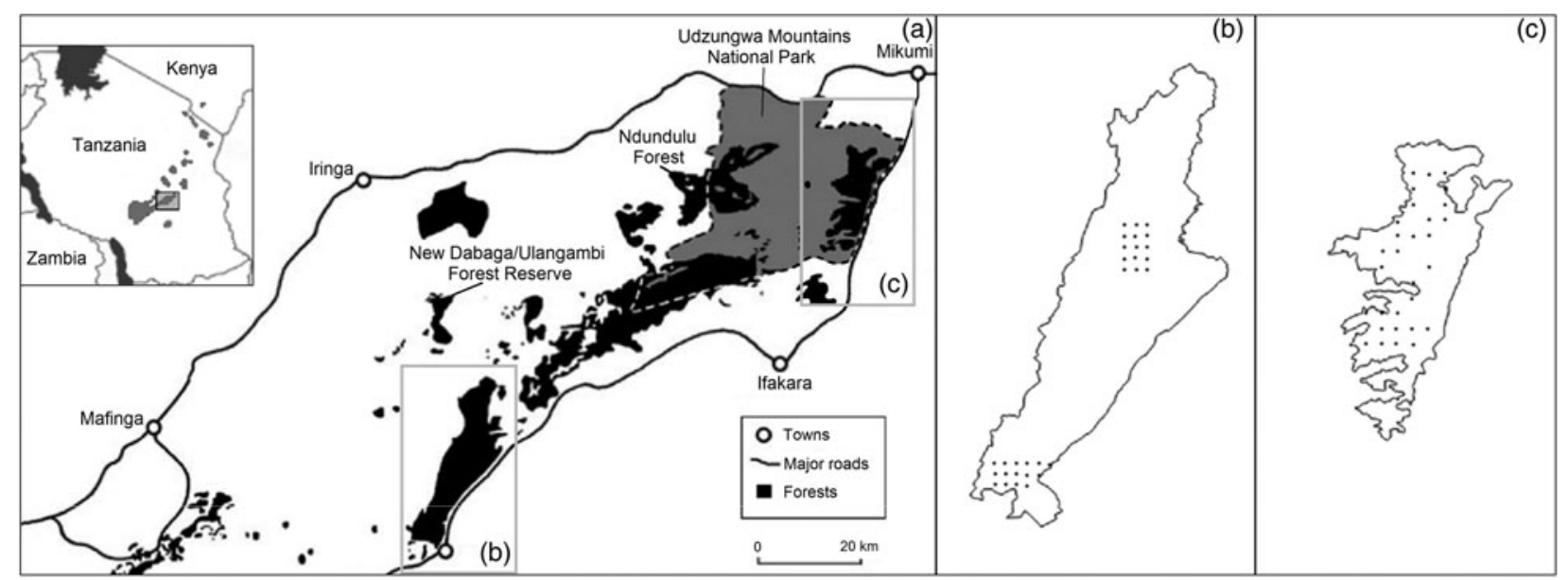

FIG. 1 Location of Uzungwa Scarp Forest Reserve and Mwanihana Forest in the Udzungwa Mountains of south-central Tanzania (a), and the location of camera traps in the Reserve (b) and Mwanihana Forest (c).

for better visibility. Elevation, canopy cover (open, closed) and the size (i.e. width) of the adjacent trail (small, medium, large) were recorded at each camera site. The distance to the forest edge (which coincides with the Reserve border) was calculated using QGIS v.2.2.o (OSGeo, Beaverton, USA). To account for variation in camera trap models used in the Reserve and in Mwanihana Forest we set one camera of each model one above the other on the same tree at two sites in the Reserve and compared the event count per species recorded by each model using a Wilcoxon test. The results indicated a marginally significant trend towards higher event counts with the cameras used in Mwanihana Forest (Wilcoxon test, $\mathrm{n}=8, \mathrm{P}=0.062$ ). However, we consider this trend unlikely to influence our results, as our analyses are based on presence and absence of species rather than their relative event count.

Camera trap data collected in Mwanihana Forest in 2013 were available through the Tropical Ecology Assessment and Monitoring (TEAM) Network project. According to a standardized protocol for monitoring terrestrial vertebrates (TEAM Network, 2011) 60 Reconyx RM45 camera traps (RECONYX, Holmen, USA), distributed over three sequential arrays of 20 cameras, were placed at a density of 1 camera per $2 \mathrm{~km}^{2}$ for a minimum of 30 days. Camera trapping was conducted during July-November 2013. To improve comparability between data from the Reserve and Mwanihana Forest 30 of the 60 cameras were selected according to the following criteria: all cameras at $>1,600 \mathrm{~m}$ $(n=4)$ were included and the remaining 26 were chosen at random from all cameras located at $>800 \mathrm{~m}$. We proceeded in this way to improve the comparability in elevation range between the camera sites in the Reserve and Mwanihana Forest: on average the 60 camera trap sites in Mwanihana Forest were located at lower elevations than those in the Reserve.
Data analyses

We used the raw data (image count) to derive standard descriptors, as follows: we counted all photographs of a species taken within an hour as one event (hourly event count), a commonly used interval to reduce the effect of multiple counts of lingering individuals (e.g. Bowkett et al., 2008; Tobler et al., 2008; Rovero \& Marshall, 2009). We calculated a relative abundance index (species-specific number of events per 100 days of camera trapping) and naïve occupancy (proportion of all sites occupied by a species) as raw indices of abundance for basic comparisons between the two sites and with other similar studies in the area. All descriptive statistics were calculated using PAST v. 2012 (Hammer et al., 2001).

To compare the species richness at both sites we estimated the number of species present in each forest according to the model developed by Dorazio et al. (2006), which accounts for imperfect detection and solves the ambiguity between absence and non-detection (MacKenzie et al., 2005; Dorazio et al., 2006). Specifically, this multispecies occupancy analytical approach models heterogeneity in species occurrence and detectability by considering speciesspecific random intercepts (i.e. mean occupancy/detectability on the linear predictor with a logit link) drawn from a normal distribution with community-level parameters (the mean and variance of the normal distribution). The outcome is a posterior Bayesian distribution of species richness. We used the R2WinBUGS package in $R$ v. 3.o.3 (R Development Core Team, 2013) to execute simulations with five Markov chains, 55,000 iterations for each chain, discarding 5,000 iterations at the beginning (burn-in) and setting the thinning rate to 50; this returns 5,000 samples from the posterior distributions. Species accumulation curves with cumulative sampling effort (i.e. camera days) 
TABLE 1 Summary of ecological characteristics and indicators of conservation effectiveness in Uzungwa Scarp Forest Reserve and Mwanihana Forest in the Udzungwa Mountains of Tanzania (Fig. 1), based on a dossier by the Government of Tanzania (2011) and a report by the Eastern Arc Mountains Conservation Endowment Fund (2013) on the conservation state of the protected areas of the Udzungwa.

\begin{tabular}{lll}
\hline Characteristics \& indicators & Uzungwa Scarp Forest Reserve & Mwanihana Forest \\
\hline Ecological factor (Lovett, 1993; Government of Tanzania, 2011) & $177 \mathrm{~km}^{2}$ \\
Area & $200 \mathrm{~km}^{2}$ & $300-2,100 \mathrm{~m}$ \\
Altitudinal range & $300-2,068 \mathrm{~m}$ & $1,750-2,000 \mathrm{~mm}$ \\
Mean annual rainfall & $1,800-2,000 \mathrm{~mm}$ & $21-31^{\circ} \mathrm{C}$ \\
Temperature range & $19-27^{\circ} \mathrm{C}$ & \\
Forest types \& elevation (m) & Woodland; $150-300 \mathrm{~m}$ & \\
& Lowland forest; $300-800 \mathrm{~m}$ & \\
& Submontane forest; $800-1,400 \mathrm{~m}$ & \\
& Montane forest; $>1,400 \mathrm{~m}$ & Several \\
Management effectiveness indicator (Eastern Arc Mountains Conservation Endowment Fund, 2013) & USD c. 400,000 \\
Vehicles (cars \& motorbikes) & None & $82 \%$ \\
Annual budget & USD c. 1,000 & 78 \\
METT score & $52 \%$ & Considerable \\
Permanent staff & 1 & Natural Resources \& Tourism \\
Infrastructure (buildings, etc.) & None & Tanzania National Parks \\
Relevant Ministry & Natural Resources \& Tourism & National Park (1992); formerly Forest Reserve \\
Government agency & Tanzania Forest Service & \\
Status & Forest Reserve (being upgraded to & \\
\hline
\end{tabular}

${ }^{*}$ METT (Management Effectiveness Tracking Tool) is a standardized measure of conservation effectiveness developed by WWF and the World Bank, which in this case included 30 factors with conservation relevance (METT < $30 \%$, poor; $31-45 \%$, average; $45-60 \%$, good; $>60 \%$, very good effectiveness; Eastern Arc Mountains Conservation Endowment Fund, 2013)

were calculated for both sites to check if the sampling effort captured a substantial portion of the species in the community (Rovero et al., 2014a). Instead of showing the quantilebased credible intervals we used the coda package in $R$ to calculate the highest posterior density intervals (Chen et al., 2000) of the posterior distributions of species richness, given these are skewed distributions.

We modelled species-specific detectabilities ( $p$, probability of detection) and occupancies ( $\psi$, proportion of sites occupied by a species), using single-species occupancy models (MacKenzie et al., 2006). Splitting the total number of trapping days into 5 -day intervals, we used repeated samplings to estimate $p$. We performed two sets of occupancy analyses using the unmarked package in $R$ (Fiske \& Chandler, 2011): firstly, we computed basic null models for species with more than five events, to compare the estimates between the two sites; secondly, we modelled $\psi$ and $p$ with relevant habitat covariates for species with 10 or more events for Uzungwa Scarp Forest Reserve. An equivalent analysis for Mwanihana Forest using data from the TEAM Network project (i.e. 60 camera trap sites) was conducted by Rovero et al. (2014a) and we used it for reference in the comparison of potential drivers of abundance of selected species. For the Reserve, the following habitat covariates were included: (1) the distance to the forest edge, coinciding with the Reserve border (affecting $p$ and $\psi$ ), assuming that species are influenced by higher hunting pressure in central forest areas and by higher habitat degradation towards the forest edges (Rovero et al., 2012); (2) the size of the trail where the camera trap was set (affecting $p$ ), assuming that species seek to avoid snares, which are preferably placed along animal trails; and (3) the canopy cover (affecting $\psi$ ), assuming that species have preferences regarding the openness of their habitat. Models were executed for all combinations of the selected covariates and ranked according to the Akaike information criterion (AIC) as a standard index for model comparison (Burnham \& Anderson, 2002; MacKenzie et al., 2006). We used model averaging to identify the critical covariates from the top-ranked models with similar AIC $(\triangle \mathrm{AIC}<2$; Burnham \& Anderson, 2002). We calculated the relative importance of the model parameters using the package AICcmodavg in $R$ (Mazerolle, 2012).

To compare the functional community composition between the two sites we grouped species into five functional guilds (carnivores, herbivores, insectivores, omnivores and rodents; Table 2) and counted the number of events within each guild. We tested for differences in the proportional event count of each guild between the two forests by using a $\chi^{2}$ test.

\section{Results}

Sampling effort was 850 (mean per camera 28.3) and 917 (mean per camera 30.6) camera days in Uzungwa Scarp Forest Reserve and Mwanihana Forest, respectively, yielding 
TABLE 2 Medium-to-large mammals detected by camera trapping in Uzungwa Scarp Forest Reserve (USFR) and Mwanihana Forest (MF), Tanzania (Fig. 1), with mass, functional guild, no. of events, relative abundance index, and naïve occupancy (no. of occupied sites divided by total no. of sites).

\begin{tabular}{|c|c|c|c|c|c|c|c|c|}
\hline \multirow[b]{2}{*}{ Species } & \multirow[b]{2}{*}{ Mass $(\mathrm{kg})$} & \multirow[b]{2}{*}{ Functional guild } & \multicolumn{2}{|c|}{ No. of events } & \multicolumn{2}{|c|}{$\begin{array}{l}\text { Relative abun- } \\
\text { dance index }\end{array}$} & \multicolumn{2}{|c|}{$\begin{array}{l}\text { Naïve } \\
\text { occupancy }\end{array}$} \\
\hline & & & USFR & MF & USFR & $\mathrm{MF}$ & USFR & MF \\
\hline \multicolumn{9}{|l|}{ Afrotheria } \\
\hline Tree hyrax Dendrohyrax validus & 2.95 & Omnivore & 3 & 41 & 0.35 & 4.47 & 0.10 & 0.37 \\
\hline African elephant Loxodonta africana & 3,900 & Herbivore & & 5 & & 0.55 & & 0.10 \\
\hline Four-toed sengi Petrodomus tetradactylus & 0.19 & Insectivore & & 1 & & 0.11 & & 0.03 \\
\hline Chequered sengi Rhynchocyon cirnei & 0.49 & Insectivore & 76 & & 8.94 & & 0.60 & \\
\hline Grey-faced sengi Rhynchocyon udzungwensis & 0.80 & Insectivore & & 42 & & 4.58 & & 0.27 \\
\hline \multicolumn{9}{|l|}{ Carnivores } \\
\hline Marsh mongoose Atilax paludinosus & 3.30 & Carnivore & & 4 & & 0.44 & & 0.10 \\
\hline Bushy-tailed mongoose Bdeogale crassicauda & 1.55 & Carnivore & 49 & 169 & 5.76 & 18.43 & 0.37 & 0.77 \\
\hline Lowe's servaline genet Genetta servalina lowei & 1.06 & Carnivore & 37 & 17 & 4.35 & 1.85 & 0.53 & 0.37 \\
\hline Honey badger Mellivora capensis & 8.50 & Omnivore & 1 & 8 & 0.12 & 0.87 & 0.03 & 0.17 \\
\hline African palm civet Nandinia binotata & 1.90 & Carnivore & 17 & 7 & 2.00 & 0.76 & 0.27 & 0.17 \\
\hline Leopard Panthera pardus & 52 & Carnivore & & 3 & & 0.33 & & 0.07 \\
\hline \multicolumn{9}{|l|}{ Primates } \\
\hline Sanje mangabey Cercocebus sanjei & 8 & Omnivore & 23 & 81 & 2.71 & 8.83 & 0.20 & 0.77 \\
\hline Sykes' monkey Cercopithecus mitis & 5 & Omnivore & 8 & 5 & 0.94 & 0.55 & 0.23 & 0.17 \\
\hline Udzungwa red colobus Procolobus gordonorum & 10 & Omnivore & & 2 & & 0.22 & & 0.07 \\
\hline \multicolumn{9}{|l|}{ Rodents } \\
\hline Giant pouched rat Cricetomys gambianus & 1.24 & Rodent & 384 & 247 & 45.18 & 26.94 & 0.83 & 0.70 \\
\hline Tanganyika mountain squirrel Paraxerus vexillarius & 0.68 & Rodent & 57 & 27 & 6.71 & 2.94 & 0.33 & 0.43 \\
\hline Greater cane rat Thryonomys swinderianus & 4.6 & Rodent & & 1 & & 0.11 & & 0.03 \\
\hline \multicolumn{9}{|l|}{ Ungulates } \\
\hline Harvey's duiker Cephalophus harveyi & 12 & Herbivore & 23 & 188 & 2.71 & 20.50 & 0.48 & 0.73 \\
\hline Blue duiker Cephalophus monticola & 6.3 & Herbivore & 6 & & 0.71 & & 0.21 & \\
\hline Abbott's duiker Cephalophus spadix & 56 & Herbivore & 10 & 32 & 1.18 & 3.49 & 0.28 & 0.57 \\
\hline Suni Neotragus moschatus & 6.5 & Herbivore & 16 & 88 & 1.88 & 9.60 & 0.21 & 0.50 \\
\hline Bush pig Potamochoerus larvatus & 48.78 & Omnivore & 4 & 8 & 0.47 & 0.87 & 0.07 & 0.17 \\
\hline African buffalo Syncerus caffer & 580 & Herbivore & & 5 & & 0.55 & & 0.10 \\
\hline Bushbuck Tragelaphus scriptus & 43 & Herbivore & & 1 & & 10.11 & & 0.03 \\
\hline
\end{tabular}

1,698 photographs (714 in the Reserve, 984 in Mwanihana) of 15 and 23 species in the Reserve and Mwanihana Forest, respectively (Table 2). The species accumulation curves reached a plateau by 200 and 250 camera days in the Reserve and Mwanihana Forest, respectively (Supplementary Fig. S2).

Estimated species richness differed significantly between the two sites, with a median of 18 (mean 19.3, highest posterior density interval $15-30$ ) and 29 species (mean 31.5 , highest posterior density interval 23-47) in the Reserve and Mwanihana Forest, respectively (i.e. mammal richness was almost $40 \%$ lower in the forest with hunting pressure; Fig. 2). At the species level, null models could be fitted for seven species detected in both forests (Harvey's duiker, suni, giant pouched rat, Tanganyika mountain squirrel Paraxerus vexillarius, Sanje mangabey Cercocebus sanjei, bushy-tailed mongoose Bdeogale crassicauda and palm civet Nandinia binotata; Table 3) and $\psi$ was lower in the Reserve for all of them except the giant pouched rat and the palm civet.
The lowest estimates of $\psi$ in the Reserve relative to the Forest were found for Sanje mangabey (Reserve: 0.23; Mwanihana: o.83), suni (Reserve: 0.25; Mwanihana: 0.51) and bushy-tailed mongoose (Reserve: 0.42; Mwanihana: 0.78), whereas the opposite pattern was found for the giant pouched rat (Reserve: 0.84; Mwanihana: 0.70); for Harvey's duiker the model did not converge (Table 3 ). Detectability was lower in the Reserve for Harvey's duiker (0.12 vs 0.55), suni (0.22 vs 0.41) and bushy-tailed mongoose (0.28 vs 0.43 ), and higher for Tanganyika mountain squirrel (0.44 vs 0.18 ) and palm civet (0.28 vs 0.12 ); for the giant pouched rat and the Sanje mangabey there was no difference in detectability between the two sites.

For five of the six species that were present at both sites and for which there were too few capture events for occupancy models, the relative abundance index was lower in the Reserve compared to Mwanihana Forest (tree hyrax Dendrohyrax validus, 0.25 vs 4.47; honey badger Mellivora capensis, 0.12 vs 0.87; Harvey's duiker, 2.71 vs 20.50; 

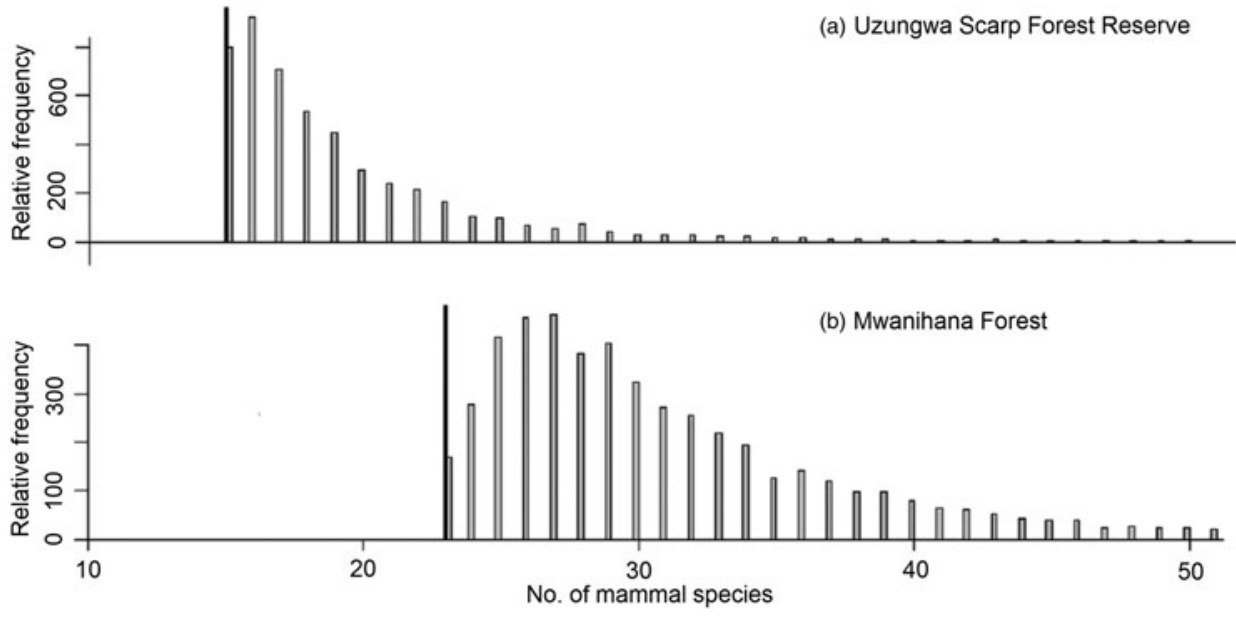

FIG. 2 Bayesian posterior distribution of species richness in (a) Uzungwa Scarp Forest Reserve and (b) Mwanihana Forest (Fig. 1). The analysis follows Dorazio et al. (2006); the vertical black line is the observed species richness, 15 and 23 in the Reserve and Mwanihana Forest, respectively, whereas the estimated median richness is 18 (mean 19.3, highest posterior density interval 15-30) and 29 species (mean 31.5, highest posterior density interval 23-47), respectively.
Abbott's duiker, 1.18 vs 3.49; bush pig Potamochoerus larvatus, o.47 vs 0.87); only Sykes' monkey Cercopithecus mitis showed the opposite pattern (0.94 vs 0.23 ).

Occupancy models with habitat covariates for the Reserve could be fitted for the seven species that were found at both sites, as well as for Lowe's servaline genet Genetta servalina lowei and the chequered sengi Rhynchocyon cirnei (see Table 4 and Supplementary Table S 1 for details of model selection). For all species at least one covariate affected $p$ or $\psi$; specifically, $p$ was affected by the distance to the forest edge, the trail size or both, whereas canopy cover did not have a significant effect for any species. The Tanganyika mountain squirrel and chequered sengi were the only species for which distance to the forest edge had a positive effect on $\psi$.

The functional community composition in the Reserve was significantly different from that in Mwanihana Forest $\left(\chi_{4}^{2}\left(\mathrm{~N}_{\text {Reserve }}=714, \mathrm{~N}_{\text {Forest }}=984\right)=292.18, \mathrm{P}<0.001\right)$. All functional guilds were affected and the biggest differences were found for rodents, which were more abundant in the Reserve, and herbivores, which were less abundant (Fig. 3).

\section{Discussion}

We have shown the potential of camera trapping in the study of bushmeat hunting, when standardized and unbiased metrics of richness and relative abundance are required. Camera trapping has only rarely been used in research on the intensity and effects of bushmeat hunting (but see Coad et al., 2013). Previous studies in the Udzungwa Mountains have been based on line transects, and dung and track counts (Topp-Jørgensen et al., 2009; Nielsen \& Treue, 2012); these methods do not facilitate accurate species identification (Bowkett et al., 2013) and do not consider detectability. Our results are therefore more likely to reflect accurately the effects of bushmeat hunting on the mammal community in Uzungwa Scarp Forest Reserve.
Our comparison between the two study sites is based on the assumption that both forests originally held equivalent communities of mammals, given their similar ecological and climatic characteristics (Table 1). The Udzungwaendemic Sanje mangabey is found only in these two forests, and many large-bodied mammals that were once present at both sites became locally extinct in the Reserve following intensive hunting in the 1970s (Rovero et al., 2012). We therefore argue that differences in the mammal communities are largely attributable to differences in hunting pressure. Two exceptions are the greyfaced sengi Rhynchocyon udzungwensis, which is found only in Mwanihana (and western Udzungwa; Rovero et al., 2008), and the blue duiker, which is found in the Reserve and a few other forests but not in Mwanihana (Rovero \& De Luca, 2007). The absence of these species in one of the two forests may be attributable to biogeographical reasons. Our results indicate that hunting has significantly altered the mammal community in the Reserve, and the loss of $40 \%$ of mammal species there demonstrates that the level of hunting pressure is not sustainable and may lead to ecological destabilization, as ecosystem resilience and stability are connected to biodiversity (Terborgh et al., 2008; Wilkie et al., 2011; McCauley et al., 2012; Effiom et al., 2014). With fewer species, webs of ecological interactions are reduced in complexity (Solé \& Montoya, 2001) and the system's resilience in response to disturbances decreases (Peterson et al., 1998; Galetti \& Dirzo, 2013). Furthermore, studies in various locations have highlighted the negative implications of loss of access to bushmeat as an essential source of protein and micronutrients for human welfare, and for children in particular (Fa et al., 2003, 2015; Golden et al., 2011), and the loss of essential non-timber forest products indirectly as a result of altered seedling demographics over time (MullerLandau, 2007; Wright et al., 2007a; Poulsen et al., 2013; Schaafsma et al., 2014). 
TABLE 3 Summary of null-model parameter estimates from occupancy modelling on the seven species recorded $>10$ times by camera traps in both Uzungwa Scarp Forest Reserve (USFR) and Mwanihana Forest (MF), in the Udzungwa Mountains of Tanzania (Fig. 1), with estimates of occupancy $(\psi)$ and detectability $(p)$.

\begin{tabular}{|c|c|c|c|c|}
\hline \multirow[b]{2}{*}{ Species } & \multicolumn{2}{|l|}{$\psi \pm \mathrm{SE}$} & \multicolumn{2}{|l|}{$p \pm S E$} \\
\hline & USFR & MF & USFR & MF \\
\hline Harvey's duiker & $0.85 \pm 0.26$ & $0.73 \pm 0.08$ & $0.12 \pm 0.04$ & $0.55 \pm 0.04$ \\
\hline Suni & $0.25 \pm 0.10$ & $0.51 \pm 0.09$ & $0.22 \pm 0.08$ & $0.41 \pm 0.05$ \\
\hline Giant pouched rat & $0.84 \pm 0.07$ & $0.70 \pm 0.08$ & $0.60 \pm 0.04$ & $0.62 \pm 0.04$ \\
\hline Tanganyika mountain squirrel & $0.34 \pm 0.09$ & $0.59 \pm 0.15$ & $0.44 \pm 0.06$ & $0.18 \pm 0.05$ \\
\hline Sanje mangabey & $0.23 \pm 0.09$ & $0.83 \pm 0.09$ & $0.27 \pm 0.07$ & $0.31 \pm 0.04$ \\
\hline Bushy-tailed mongoose & $0.42 \pm 0.11$ & $0.78 \pm 0.08$ & $0.28 \pm 0.06$ & $0.43 \pm 0.04$ \\
\hline Palm civet & $0.30 \pm 0.10$ & $0.29 \pm 0.17$ & $0.28 \pm 0.07$ & $0.12 \pm 0.07$ \\
\hline
\end{tabular}

TABLE 4 Summary of results of occupancy analyses with habitat covariates for mammals detected in Uzungwa Scarp Forest Reserve, Tanzania (Fig. 1). Models tested the influence of canopy cover on occupancy $\psi$ (canopy [coverage]), distance to the forest edge on occupancy $\psi$ (edge), distance to the forest edge on detectability $p$ (edge), and trail size on detectability $p$ (trail [size]), with significant factor levels (i.e. small/medium/large trail size, open/closed canopy) of factorial covariates in [ ]. A significant $(\mathrm{P}<0.05)$ influence of a covariate is indicated by - for a negative and + for a positive effect. A marginally significant influence $(\mathrm{P}<0.10)$ is shown in () .

\begin{tabular}{|c|c|c|c|c|}
\hline Species & $\psi($ canopy [coverage] $)$ & $\psi($ edge $)$ & $p$ (edge) & $p($ trail $[$ size $])$ \\
\hline Harvey's duiker & & & - & \\
\hline Suni & & & & $\begin{array}{l}{[\text { small] }(-)} \\
{[\text { medium] }(-)}\end{array}$ \\
\hline Giant pouched rat & & & - & {$[$ small $](-)$} \\
\hline Tanganyika mountain squirrel & & + & $(+)$ & \\
\hline Sanje mangabey & & & - & \\
\hline Bushy-tailed mongoose & & & - & {$[$ small $](-)$} \\
\hline Palm civet & & & & [small] $(+)$ \\
\hline Lowe's servaline genet & & & & [small] $(-)$ \\
\hline Chequered sengi & & $(+)$ & & [small] $(+)$ \\
\hline
\end{tabular}

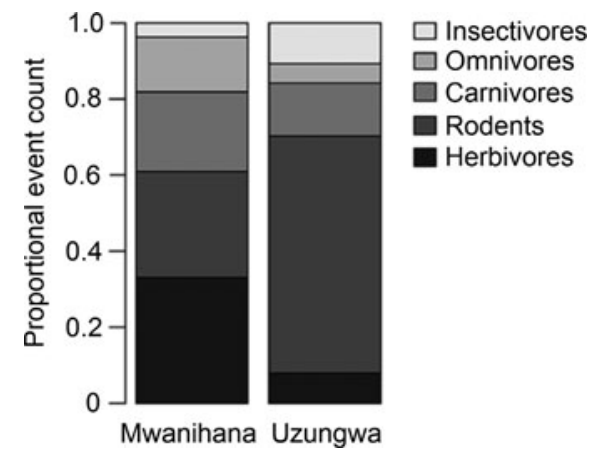

FIG. 3 Proportional event count for each functional guild in Uzungwa Scarp Forest Reserve and Mwanihana Forest (Fig. 1). The community composition is significantly different between the two sites $\left(\chi_{4}^{2}\left(\mathrm{~N}_{\mathrm{USFR}}=714, \mathrm{~N}_{\mathrm{MF}}=984\right)=292.18, \mathrm{P}<0.001\right)$.

For the majority of species, occupancy estimates were lower in the Reserve than in Mwanihana Forest, and for five of the six species with too few captures to estimate occupancy both the relative abundance index and naïve occupancy were lower in the Reserve. Species' responses to hunting are influenced by species-specific vulnerabilities
(Isaac \& Cowlishaw, 2004; Linder \& Oates, 2011), and indirectly by the alterations of interspecific interactions (i.e. competitive and/or predator release; Peres, 2000). Not surprisingly the relative abundance index for all preferably hunted species still present in both forests was substantially lower in the hunted forest. The number of hourly events was too low for model convergence for several of these species, such as Abbott's duiker, blue duiker and tree hyrax. The occupancy estimate for suni in the reserve was half that estimated for Mwanihana Forest. For the Udzungwa-endemic Sanje mangabey, occupancy in the Reserve was nearly a quarter of that in Mwanihana Forest, contrary to an earlier study that reported this species as common in both forests as a result of its ecological adaptability (Rovero et al., 2012). The study was based on line transect counts mainly in the lower zones of the forests but our results are based on a more robust method and cover a more representative area, and therefore may be more accurate. The occupancy of species not preferred by hunters, such as the bushy-tailed mongoose, also differed between the two forests; this may reflect indirect effects such as competitive and/or predator release. Such processes, which are difficult to study, may be 
common in hunted rainforests (Peres \& Dolman, 2000; Wright, 2003); for example, a study based on repeated transect surveys in the adjacent Kilombero nature reserve found declining densities of Abbott's duiker and bush pig associated with increased densities of blue and Harvey's duikers, interpreted as a likely effect of competitive release (Nielsen, 2011).

The interpretation of differences in detectability between forests is not straightforward, as it may be influenced by a range of factors (Rovero et al., 2014a). It highlights the importance of accounting for detectability when comparing populations, and how assessments based on raw indices (e.g. Topp-Jørgensen et al., 2009; Rovero et al., 2012) may lead to biased results; for example, lower detectabilities for the hunted Harvey's duiker and suni in the Reserve may be explained by decreased mobility and/or reduced home ranges as a result of higher levels of human disturbance (Newing, 2001; Mockrin, 2010). Furthermore, hunting avoidance behaviour may explain the influence of the size of animal trails on the detectability of several species, as hunters in the Reserve prefer to set their snares on wide animal trails (M.R. Nielsen, unpubl. data). Studies on behavioural adaptations to hunting are rare, although some evidence exists for duikers and primates in Gabon and Ivory Coast (Bshary, 2001; Croes et al., 2007). Weckel et al. (2006) and Harmsen et al. (2010) found that mediumsized mammals avoided larger trails when facing a higher risk of encounters with predators, indicating that mammals adapt their behaviour to specific dangers.

The differences in functional composition of the two communities appeared to be explained by the hunting levels in the Reserve: whereas the variance in the relative abundances of all five guilds was low in Mwanihana Forest (o.o1), the Reserve was dominated by rodents at the expense of all other guilds except insectivores, and the variance was six times higher (0.06, Fig. 3). These findings match those of Ahumada et al. (2011), who compared several mammal communities and showed how markedly functional guilds can differ in their responses to human disturbance. Such changes in community composition may also affect plantanimal interactions in the Reserve (Fjeldså \& Lovett, 1997), including seed predation and dispersal, seedling survival and plant regeneration (Wright, 2003; Muller-Landau, 2007; Wright et al., 2007a,b).

Two potential confounding factors need to be considered when interpreting our results. Firstly, besides hunting, logging and firewood collection may also affect mammal abundance and eventually lead to local extinction of some species (Laurance et al., 2006; Arroyo-Rodríguez \& Dias, 2010; Rovero et al., 2012) and increased density of others (Nummelin, 1990; Wilkie \& Finn, 1990). Intensive logging occurs mainly towards the lower edge of the Reserve, and therefore we placed camera traps in the forest interior, $231-4,586 \mathrm{~m}$ from the forest edge, where logging does not occur and hunting is likely to be more intense (Rovero et al., 2012; C. Hegerl, unpubl. data). Secondly, the differences in sampling season and area coverage between the two sites may be a source of bias in our results. However, we believe that seasonal fluctuations in species' abundance and detectability cannot account for the differences we found, as despite extensive work in both forests no seasonal movements in or out of the forest area have been documented for the medium-sized forest-dwelling species considered in this study. Furthermore, preliminary results from a study that compared occupancy and detectability between wet and dry seasons in Mwanihana Forest indicate that neither parameter changed significantly (E. Martin \& F. Rovero, unpubl. data). The surveying of a smaller area in the Reserve compared to Mwanihana Forest was a result of logistical constraints related to the accessibility and roughness of the terrain in the former relative to the latter. Furthermore the $2 \mathrm{~km}$ grid cell size adopted by the TEAM protocol in Mwanihana Forest is mainly relevant to large mammals with home ranges larger than the grid cell size, whereas our study focused on small- to medium-sized mammals with home ranges that we assumed to be smaller than the grid cell size.

Although our study was limited to some extent by sample size, we provide evidence of the impact of bushmeat hunting on the mammal community in one of the most biologically important forests within the Udzungwa Mountains and the whole Eastern Arc. Enforcement of existing regulations prohibiting hunting is important, but evidence from the adjacent Kilombero Valley indicates that the availability of alternative income-generating options has a greater effect on the decision whether or not to engage in hunting (Nielsen et al., 2014). The study found that $90 \%$ of the actors in the bushmeat value chain would cease their illegal activities if an alternative job paying c. USD 3 per day was available. Local communities must be given the expertise and power to take an active part in the implementation of conservation measures, as long-term changes will only be possible if local livelihoods are not negatively affected (Nielsen \& Treue, 2012).

\section{Acknowledgements}

We thank two anonymous reviewers for valuable comments. Permits for data collection were granted by the Tanzania Wildlife Research Institute, Tanzania Commission for Science and Technology, Forestry and Beekeeping Division and Tanzania National Parks. Data for Mwanihana were provided by the Tropical Ecology Assessment and Monitoring Network (a collaboration between Conservation International, the Missouri Botanical Garden, the Smithsonian Institution, and the Wildlife Conservation Society, partially funded by these institutions, the Gordon and Betty Moore 
Foundation and other donors). Funding for this project was provided by the German Academic Exchange Service, MUSE-Museo delle Scienze (Trento, Italy), and Uppsala University; University of Trento funded the camera traps for Uzungwa Scarp. We are grateful to the staff at the Udzungwa Ecological Monitoring Centre who provided critical logistical support, and to field assistants Ruben Mwakisoma, Steven Shinyambala and Aggrey Uisso, as well as Elisa Cattani, for their invaluable help.

\section{References}

Ahumada, J.A., Silva, C.E.F., Gajapersad, K., Hallam, C., Hurtado, J., Martin, E. et al. (2011) Community structure and diversity of tropical forest mammals: data from a global camera trap network. Philosophical Transactions of the Royal Society B, 366 , 2703-2711.

Arroyo-Rodríguez, V. \& Dias, P.A.D. (2010) Effects of habitat fragmentation and disturbance on howler monkeys: a review. American Journal of Primatology, 72, 1-16.

Bennett, E.L., Blencowe, E., Brandon, K., Brown, D., Burn, R. W., Cowlishaw, G. et al. (2007) Hunting for consensus: reconciling bushmeat harvest, conservation, and development policy in West and Central Africa. Conservation Biology, 21, 884-887.

Bownett, A.E., Rovero, F. \& Marshall, A.R. (2008) The use of camera-trap data to model habitat use by antelope species in the Udzungwa Mountain forests, Tanzania. African Journal of Ecology, $46,479-487$.

Bowkett, A.E., Jones, T., Laizzer, R.L., Plowman, A.B. \& Stevens, J.R. (2013) Can molecular data validate morphometric identification of faecal pellets in Tanzanian forest antelope species? Conservation Genetics Resources, 5, 1095-1100.

Brashares, J.S., Arcese, P. \& SAM, M.K. (2001) Human demography and reserve size predict wildlife extinction in West Africa. Proceedings of the Royal Society B, 268, 2473-2478.

Bshary, R. (2001) Diana monkeys, Cercopithecus diana, adjust their anti-predator response behaviour to human hunting strategies. Behavioral Ecology and Sociobiology, 50, 251-256.

Burgess, N.D., Butynski, T.M., Cordeiro, N.J., Doggart, N.H., FjeldSÅ, J., Howell, K.M. et al. (2007) The biological importance of the Eastern Arc Mountains of Tanzania and Kenya. Biological Conservation, 134, 209-231.

Burnham, K.P. \& Anderson, D.R. (2002) Model Selection and Multimodel Inference: A Practical Information-Theoretic Approach, and edition. Springer, New York, USA.

Chen, M.-H., Shao, Q.-M. \& Ibrahim, J.G. (2000) Monte Carlo Methods in Bayesian Computation. Springer, New York, USA.

Coad, L., Schleicher, J., Milner-Gulland, E.J., Marthews, T.R., Starkey, M., Manica, A. et al. (2013) Social and ecological change over a decade in a village hunting system, Central Gabon. Conservation Biology, 27, 270-280.

Croes, B.M., Laurance, W.F., Lahm, S.A., Tchignoumba, L., Alonso, A., Lee, M.E. et al. (2007) The influence of hunting on antipredator behavior in Central African monkeys and duikers. Biotropica, 39, 257-263.

Cullen, Jr, L., Bodmer, R.E. \& PÁdua, C.V. (2000) Effects of hunting in habitat fragments of the Atlantic forests, Brazil. Biological Conservation, 95, 49-56.

DeFries, R., Rovero, F., Wright, P., Ahumada, J., Andelman, S., BRANDON, K. et al. (2010) From plot to landscape scale: linking tropical biodiversity measurements across spatial scales. Frontiers in Ecology and the Environment, 8, 153-160.

Dorazio, R.M., Royle, J.A., Söderström, B. \& Glimskär, A. (2006) Estimating species richness and accumulation by modeling species occurrence and detectability. Ecology, 87, 842-854.

Eastern Arc Mountains Conservation Endowment Fund (2013) Baseline Survey Report in 8 Nature Reserves and 1 National Park in the Eastern Arc Mountains of Tanzania. Sokoine University of Agriculture, Morogoro, Tanzania.

Effiom, E.O., Birkhofer, K., Smith, H.G. \& Olsson, O. (2014) Changes of community composition at multiple trophic levels due to hunting in Nigerian tropical forests. Ecography, 37, 367-377.

Effiom, E.O., Nuñez-Iturri, G., Smith, H.G., Ottosson, U. \& Olsson, O. (2013) Bushmeat hunting changes regeneration of African rainforests. Proceedings of the Royal Society B, 280, 20130246.

FA, J.E. \& Brown, D. (2009) Impacts of hunting on mammals in African tropical moist forests: a review and synthesis. Mammal Review, 39, 231-264.

FA, J.E., Currie, D. \& Meeuwig, J. (2003) Bushmeat and food security in the Congo Basin: linkages between wildlife and people's future. Environmental Conservation, 30, 71-78.

Fa, J.E., Olivero, J., Real, R., Farfán, M.A., Márquez, A.L., VARGAS, J.M. et al. (2015) Disentangling the relative effects of bushmeat availability on human nutrition in central Africa. Scientific Reports, 5, 8168.

FA, J.E., Peres, C.A. \& Meeuwig, J. (2002) Bushmeat exploitation in tropical forests: an intercontinental comparison. Conservation Biology, 16, 232-237.

Fiske, I.J. \& CHANDLER, R.B. (2011) unmarked: an R package for fitting hierarchical models of wildlife occurrence and abundance. Journal of Statistical Software, 43, 1-23.

FJeLdSÅ, J. \& LovetT, J.C. (1997) Biodiversity and environmental stability. Biodiversity and Conservation, 6, 315-323.

Galetti, M. \& Dirzo, R. (2013) Ecological and evolutionary consequences of living in a defaunated world. Biological Conservation, 163, 1-6.

Golden, C.D., Fernald, L.C.H., Brashares, J.S., Rasolofoniaina, B.J.R. \& KREMEN, C. (2011) Benefits of wildlife consumption to child nutrition in a biodiversity hotspot. PNAS, 108, 19653-19656.

Government of Tanzania (2011) Nomination of Properties for Inclusion on the World Heritage List Serial Nomination: Eastern Arc Mountains Forests of Tanzania. Ministry of Natural Resources and Tourism, Dar es Salaam, Tanzania.

Hammer, Ø., Harper, D.A.T. \& Ryan, P.D. (2001) PAST: Paleontological statistics software package for education and data analysis. Paleontologia Electronica, 4, 1-9.

Harmsen, B.J., Foster, R.J., Silver, S., Ostro, L. \& Doncaster, C.P. (2010) Differential use of trails by forest mammals and the implications for camera-trap studies: a case study from Belize. Biotropica, 42, 126-133.

IsAaC, N.J.B. \& Cowlishaw, G. (2004) How species respond to multiple extinction threats. Proceedings of the Royal Society B, 271, $1135-1141$.

Jerozolimski, A. \& Peres, C.A. (2003) Bringing home the biggest bacon: a cross-site analysis of the structure of hunter-kill profiles in Neotropical forests. Biological Conservation, 111, 415-425.

Laurance, W.F., Croes, B.M., Tchignoumba, L., Lahm, S.A., Alonso, A., Lee, M.E. et al. (2006) Impacts of roads and hunting on central African rainforest mammals. Conservation Biology, 20, 1251-1261.

LindeR, J.M. \& OAtes, J.F. (2011) Differential impact of bushmeat hunting on monkey species and implications for primate 
conservation in Korup National Park, Cameroon. Biological Conservation, 144, 738-745.

Lovett, J.C. (1993) Climatic history and forest distribution in eastern Africa. In Biogeography and Ecology of the Rain Forests of Eastern Africa (eds J.C. Lovett \& S.K. Wasser), pp. 23-30. Cambridge University Press, Cambridge, UK.

MacKenzie, D.I., Nichols, J.D., Lachman, G.B., Droege, S., Royle, J.A. \& Langtimm, C.A. (2002) Estimating site occupancy rates when detection probabilities are less than one. Ecology, 83, 2248-2255.

MacKenzie, D.I., Nichols, J.D., Royle, J.A., Pollock, K.H., BAiley, L.L. \& Hines, J.E. (2006) Occupancy Estimation and Modeling. Academic Press, Burlington, USA.

MacKenzie, D.I., Nichols, J.D., Sutton, N., Kawanishi, K. \& Bailey, L.L. (2005) Improving inferences in population studies of rare species that are detected imperfectly. Ecology, 86, 1101-1113.

Mazerolle, M.J. (2012) AICcmodavg: model selection and multi-model inference based on (Q)AIC(c). R package version 1.26 . Http://cran.r-project.org/web/packages/AICcmodavg/index.html [accessed 12 March 2015].

McCauley, D.J., DeSalles, P.A., Young, H.S., Dunbar, R.B., Dirzo, R., Mills, M.M. \& Micheli, F. (2012) From wing to wing the persistence of long ecological interaction chains in less-disturbed ecosystems. Scientific Reports, 2, 1-5.

Milner-Gulland, E.J. \& Bennet T, E.L. (2003) Wild meat: the bigger picture. Trends in Ecology \& Evolution, 18, 351-357.

Mockrin, M.H. (2010) Duiker demography and dispersal under hunting in Northern Congo. African Journal of Ecology, 48, 239-247.

Muller-Landau, H.C. (2007) Predicting the long-term effects of hunting on plant species composition and diversity in tropical forests. Biotropica, 39, 372-384.

Museo Tridentino di Scienze Naturali (2007) Conservation Status, Connectivity, and Options for Improved Management of Southern Forest Reserves in the Udzungwa Mountains, Tanzania: Urgent Need for Intervention. Report to the Critical Ecosystem Partnership Fund. Trento Museum of Natural Sciences, Trento, Italy.

National Bureau of Statistics (2013) Population and Housing Census. Ministry of Finance, Dar es Salaam, Tanzania.

NEWING, H. (2001) Bushmeat hunting and management: implications of duiker ecology and interspecific competition. Biodiversity and Conservation, 10, 99-118.

Nielsen, M.R. (2006) Importance, cause and effect of bushmeat hunting in the Udzungwa Mountains, Tanzania: implications for community based wildlife management. Biological Conservation, $128,509-516$.

Nielsen, M.R. (2011) Improving the conservation status of the Udzungwa Mountains, Tanzania? The effect of joint forest management on bushmeat hunting in the Kilombero nature reserve. Conservation \& Society, 9, 106-118.

Nielsen, M.R., Jacobsen, J.B. \& Thorsen, B.J. (2014) Factors determining the choice of hunting and trading bushmeat in the Kilombero Valley, Tanzania. Conservation Biology, 28, 382-391.

Nielsen, M.R. \& Treue, T. (2012) Hunting for the benefits of joint forest management in the Eastern Afromontane Biodiversity Hotspot: effects on bushmeat hunters and wildlife in the Udzungwa Mountains. World Development, 40, 1224-1239.

Nummelin, M. (1990) Relative habitat use of duikers, bush pigs, and elephants in virgin and selectively logged areas of the Kibale Forest, Uganda. Tropical Zoology, 3, 111-120.

Nyundo, B.A., Mtui, A. \& Kissaka, H. (2006) An Assessment of Ecological and Social-Economic Impacts Caused by Collection of Deadwood, Medicinal Plants and Cutting of Grass for Thatching in
Udzungwa Mountains National Park. Unpublished report for WWF-Tanzania Programme, Dar es Salaam, Tanzania.

O'Brien, T.G. (2011) Abundance, density and relative abundance: a conceptual framework. In Camera Traps in Animal Ecology: Methods and Analyses (eds A.F. O'Connell, J.D. Nichols \& K. U. Karanth), pp. 71-96. Springer, New York, USA.

Peres, C.A. (2000) Effects of subsistence hunting on vertebrate community structure in Amazonian forests. Conservation Biology, $14,240-253$.

Peres, C.A. \& Dolman, P.M. (2000) Density compensation in neotropical primate communities: evidence from 56 hunted and nonhunted Amazonian forests of varying productivity. Oecologia, 122, 175-189.

Peterson, G., Allen, C.R. \& Holling, C.S. (1998) Ecological resilience, biodiversity, and scale. Ecosystems, 1, 6-18.

Poulsen, J.R., Clark, C.J. \& Bolker, B.M. (2011) Decoupling the effects of logging and hunting on an Afrotropical animal community. Ecological Applications, 21, 1819-1836.

Poulsen, J.R., Clark, C.J. \& Palmer, T.M. (2013) Ecological erosion of an Afrotropical forest and potential consequences for tree recruitment and forest biomass. Biological Conservation, 163, 122-130.

R Development Core Team (2013) R: A Language and Environment for Statistical Computing. R Foundation for Statistical Computing, Vienna, Austria.

Redford, K.H. (1992) The empty forest. BioScience, 42, 412-422.

Rist, J., Milner-Gulland, E.J., Cowlishaw, G. \& Rowcliffe, J.M. (2009) The importance of hunting and habitat in determining the abundance of tropical forest species in Equatorial Guinea. Biotropica, 41, 700-710.

Robinson, J.G. \& BennetT, E.L. (2004) Having your wildlife and eating it too: an analysis of hunting sustainability across tropical ecosystems. Animal Conservation, 7, 397-408.

Rovero, F. \& De Luca, D.W. (2007) Checklist of mammals of the Udzungwa Mountains of Tanzania. Mammalia, 71, 47-55.

Rovero, F. \& Marshall, A.R. (2009) Camera trapping photographic rate as an index of density in forest ungulates. Journal of Applied Ecology, 46, 1011-1017.

Rovero, F., Marshall, A.R., Jones, T. \& Perkin, A. (2009) The primates of the Udzungwa Mountains: diversity, ecology and conservation. Journal of Anthropological Sciences, 87, 93-126.

Rovero, F., Martin, E., Rosa, M., Ahumada, J.A. \& Spitale, D. (2014a) Estimating species richness and modelling habitat preferences of tropical forest mammals from camera trap data. PLoS ONE, 9(7), e103300.

Rovero, F., Menegon, M., Fjeldså, J., Collett, L., Doggart, N., LEONARD, C. et al. (2014b) Targeted vertebrate surveys enhance the faunal importance and improve explanatory models within the Eastern Arc Mountains of Kenya and Tanzania. Diversity and Distributions, 20, 1438-1449.

Rovero, F., Mtui, A., Kitegile, A., Nielsen, M. \& Jones, T. (2010) Uzungwa Scarp Forest Reserve in Crisis: An Urgent Call to Protect one of Tanzania's Most Important Forests. Report by Tanzania Forest Conservation Group, Wildlife Conservation SocietyTanzania Programme, Dar es Salaam, Tanzania.

Rovero, F., Mtui, A.S., Kitegile, A.S. \& Nielsen, M.R. (2012) Hunting or habitat degradation? Decline of primate populations in Udzungwa Mountains, Tanzania: an analysis of threats. Biological Conservation, 146, 89-96.

Rovero, F., Rathbun, G.B., Perkin, A., Jones, T., Ribble, D.O., LEONARD, C. et al. (2008) A new species of giant sengi or elephant-shrew (genus Rhynchocyon) highlights the exceptional biodiversity of the Udzungwa Mountains of Tanzania. Journal of Zoology, 274, 126-133. 
Rovero, F., Zimmermann, F., Berzi, D. \& Meek, P. (2013) “Which camera trap type and how many do I need?" A review of camera features and study designs for a range of wildlife research applications. Hystrix, The Italian Journal of Mammalogy, 24, 148-156.

Schaffsma, M., Morse-Jones, S., Posen, P., Swetnam, R.D., BALmFord, A., BAtEmAn, I.J. et al. (2014) The importance of local forest benefits: economic valuation of non-timber forest products in the Eastern Arc Mountains in Tanzania. Global Environmental Change, 24, 295-305.

Shangali, C.F., Mabula, C.K. \& Mmari, C. (1998) Biodiversity and human activities in the Udzungwa Mountain Forests,

Tanzania. 1. Ethnobotanical survey in the Uzungwa Scarp Forest Reserve. Journal of East African Natural History, 87, 291-318.

Silveira, L., JÁcomo, A.T.A. \& Diniz-Filho, J.A.F. (2003) Camera trap, line transect census and track surveys: a comparative evaluation. Biological Conservation, 114, 351-355.

Solé, R.V. \& Montoya, J.M. (2001) Complexity and fragility in ecological networks. Proceedings of the Royal Society B, 268, 20392045.

Taylor, G., Scharlemann, J.P.W., Rowcliffe, M., Kümpel, N., Harfoot, M.B.J., FA, J.E. et al. (2015) Synthesising bushmeat research effort in West and Central Africa: a new regional database. Biological Conservation, 181, 199-205.

TEAM Network (2011) Terrestrial Vertebrate Monitoring Protocol v. 3.1. Conservation International, Arlington, USA.

Terborgh, J., Nuñez-Iturri, G., Pitman, N.C.A., Valverde, F.H. C., Alavrez, P., Swamy, V. et al. (2008) Tree recruitment in an Empty Forest. Ecology, 89, 1757-1768.

Tobler, M.W., Carrillo-Percastegui, S.E., Leite Pitman, R., Mares, R. \& Powell, G. (2008) An evaluation of camera traps for inventorying large- and medium-sized terrestrial rainforest mammals. Animal Conservation, 11, 169-178.

Topp-Jørgensen, E., Nielsen, M.R., Marshall, A.R. \& Pedersen, U. (2009) Mammalian density in response to different levels of bushmeat hunting in the Udzungwa Mountains, Tanzania. Tropical Conservation Science, 2, 70-87.

Weckel, M., Giuliano, W. \& Silver, S. (2006) Jaguar (Panthera onca) feeding ecology: distribution of predator and prey through time and space. Journal of Zoology, 270, 25-30.
Wilkie, D.S., Bennett, E.L., Peres, C.A. \& Cunningham, A.A. (2011) The empty forest revisited. Annals of the New York Academy of Sciences, 1223, 120-128.

Wilkie, D.S. \& FinN, J.T. (1990) Slash-burn cultivation and mammal abundance in the Ituri Forest, Zaire. Biotropica, 22, 90-99.

Williams, B.K., Nichols, J.D. \& Conroy, M.J. (2002) Analysis and Management of Animal Populations. Academic Press, San Diego, USA.

Wright, S.J. (2003) The myriad consequences of hunting for vertebrates and plants in tropical forests. Perspectives in Plant Ecology, Evolution and Systematics, 6, 73-86.

Wright, S.J., Hernandéz, A. \& Condit, R. (2007a) The bushmeat harvest alters seedling banks by favoring lianas, large seeds, and seeds dispersed by bats, birds, and wind. Biotropica, 39, 363-371.

Wright, S.J., Stoner, K.E., Beckman, N., Corlett, R.T., Dirzo, R., Muller-Landau, H.C. et al. (2007b) The plight of large animals in tropical forests and the consequences for plant regeneration. Biotropica, 39, 289-291.

Yoccoz, N.G., Nichols, J.D. \& Boulinier, T. (2001) Monitoring of biological diversity in space and time. Trends in Ecology \& Evolution, 16, 446-453.

\section{Biographical sketches}

CARLa Hegerl is interested in applied conservation and ecological modelling. NEIL BURGESS works at the interface between science and policy and has managed large-scale conservation projects in Tanzania. MARTin Nielsen works on the human dimensions of wildlife management, focusing on bushmeat hunting and the design of management strategies. EMANUEL MARTIN's research focuses on the use of camera traps for studying temporal and spatial variations of forest mammals in the Udzungwa Mountains. MARCo Ciolli is a forest ecologist whose research focuses on the application and development of geographical information systems, and on forestry and ecological planning in mountain environments. FRANCESCO ROVERO is a zoologist and conservation ecologist who focuses on ecological modelling of tropical forest mammals, and uses camera trapping extensively. 